\title{
A Mixed Layerwise-Differential Quadrature Method for 3-D Vibration and Buckling Analyses of Orthogonally Stiffened Composite Conical Shell
}

\author{
Mostafa Talebitooti \\ Department of Mechanical Engineering, Qom University of Technology, Khoda Karam St., 37195-1519 Qom, Iran.
}

(Received 25 October 2015; accepted 24 June 2016)

\begin{abstract}
A layerwise-differential quadrature method (LW-DQM) is developed for the vibration analysis of a stiffened laminated conical shell. The circumferential stiffeners (rings) and meridional stiffeners (stringers) are treated as discrete elements. The motion equations are derived by applying the Hamilton's principle. In order to accurately account for the thickness effects and the displacement field of stiffeners, the layerwise theory is used to discretize the equations of motion and the related boundary conditions through the thickness. Then, the equations of motion as well as the boundary condition equations are transformed into a set of algebraic equations applying the DQM in the meridional direction. The advantage of the proposed model is its applicability to thin and thick unstiffened and stiffened shells with arbitrary boundary conditions. In addition, the axial load and external pressure is applied to the shell as a ratio of the global buckling load and pressure. This study demonstrates the accuracy, stability, and the fast rate of convergence of the present method, for the buckling and vibration analyses of stiffened conical shells. The presented results are compared with those of other shell theories and a special case where the angle of conical shell approaches zero, i.e. a cylindrical shell, and excellent agreements are achieved.
\end{abstract}

\section{INTRODUCTION}

Stiffened conical shells are increasingly being used in a variety of aerospace, aeronautical, naval and civil structures including launch vehicles, the space-shuttle solid rocket booster, and submarines because of their strength to weight ratio. Hence, it is of a great importance to understand the mechanical behaviour of stiffened conical shells for the design of aforementioned structures. The primary concerns are the global buckling load, vibration and the effect of the axial load, and pressure on natural frequency. Most of the previous studies on stability and vibration of shells have focused on stiffened cylindrical shells and unstiffened conical shell based on classical laminated shell theory (CLT).

The buckling of simply supported cylindrical shells under hydrostatic pressure was analysed by Baruch and Singer, and the properties of the stiffeners were averaged over the shell surface by the smearing method. ${ }^{1}$ A discrete-ring theory for stiffened isotropic cylinders with neglecting pre-buckling deformations is developed by Hedgepeth and Hall. ${ }^{2}$ Further analysis of the buckling loads of composite cylindrical shells with axial and circumferential stiffeners can be found in a later work by Reddy and Starnes using a layerwise shell theory and smearing out method. ${ }^{3}$ Patel et al. concentrated on the static and dynamic instability characteristics of different stiffened shell panel types such as flat plate, cylindrical shell panel, spherical shell panel, and hyperbolic hyperboloid shell. ${ }^{4}$ Jiang et al. used the differential quadrature element method for the first time to obtain buckling loads of stiffened, circular, cylindrical panels subjected to uniform distributed axial compression. ${ }^{5}$ Seide recommended a formula for buckling of isotropic conical shells which is independent of boundary conditions and best fits the behaviour of long shells. ${ }^{6}$ An experimental investigation of the effect of the cone semi-vertex angle on the buck- ling load of a conical shell under axial compression was carried out by Arbocz. ${ }^{7}$ Tong et al. presented a simple and exact procedure using Donnell-type shell theory for linear buckling analysis of orthotropic conical shells under axial compressive loads and external pressure. ${ }^{8}$ Tong and Wang obtained eight first-order differential equations for linear buckling analysis of laminated conical shells, with orthotropic stretching-bending, coupling, under axial compressive load. ${ }^{9} \mathrm{Wu}$ and Chen developed asymptotic solutions for buckling analysis of multilayered anisotropic conical shells under axial compression on the basis of 3D elasticity. ${ }^{10}$ Sofiyev and Schnack studied the buckling of cross-ply laminated, orthotropic, truncated, circular conical thin shells with variable Young's moduli and densities in the thickness direction, subjected to a uniform external pressure which is a power function of time. ${ }^{11}$ Recently, Shadmehri et al. proposed a semi-analytical approach to obtain the linear buckling response of conical composite shells under axial compression load based on first order shear deformation shell theory. ${ }^{12}$ Also, a generalized beam theory (GBT) formulation is developed to analyse the elastic buckling behaviour of isotropic conical shells with constant thickness under axial compression by Nedelcu. ${ }^{13}$ More recently, the first-order shear deformation shell theory is employed to investigate buckling of heterogeneous and non-homogeneous orthotropic conical shells subjected to combined load. ${ }^{14,15}$ In addition, few studies have been published targeting the buckling behaviour of stiffened conical composite shells. They include the works by Spagnoli and Chryssanthopoulos on the buckling and postbuckling elastic behaviour of stringer stiffened conical panels using a finite element model and an equivalent cylinder approach. ${ }^{16,17}$ Moreover, Spagnoli studied the different modes of instability in stringer-stiffened cones under axial compression through finite element. ${ }^{18}$ 
For vibration of unstiffened conical shell, many papers discuss the frequency characteristics based on CLT, particularly the works done by Sivadas and Ganesan, ${ }^{19}$ Thambiratnam and Zhuge, ${ }^{20}$ Tong, ${ }^{21,22}$ and Sofiyev et al. ${ }^{23,24}$ Additionally, Najafov et al. derived the governing equations for non-linear free vibration of truncated, thin, laminated, orthotropic conical shells using the theory of large deformations. ${ }^{25}$ This theory cannot be used for thick shells and even thin shells when the number of circumferential waves increases as a result of neglecting shear deformation and rotary inertia effects in CLT. On the other hand, little research has been found on stiffened conical shell. ${ }^{26-34}$ Besides, this research just focuses on conical shells and the stiffeners have been modelled using smearing methods except for the work directed by Talebitooti et al. ${ }^{34}$ They assessed natural frequency of rotating stiffened conical shell in which the stiffeners are modelled by discrete elements based on CLT. Also, the refinement of thin-shell theories has resulted in a number of the so-called first- and higher-order shear deformation theories to include the effects of transverse shear deformations. ${ }^{35-42}$ These theories are much more accurate than the thin-shell theories in an analysis of moderately thick shells, but they are still inadequate for an analysis of thick and stiffened shells. In order to analyse thick and/or stiffened conical shells accurately, a three-dimensional theory should be used to take into account all transverse stress and strain components.

In recent years, the new numerical method, so-called hybrid layerwise-differential quadrature method (LW-DQM), is employed to discretize the governing equations of structures. ${ }^{43-46}$ In contrast to the equivalent single layer theories (ESLT), the layerwise theories develop the separate displacement field expansions through each subdivision. The displacement components are continuous through the laminate thickness but their derivatives with respect to the thickness coordinate may be discontinuous at various points through the thickness, thereby allowing for possibility of continuous transverse stress at interfaces separating contradictory materials. ${ }^{47}$ Furthermore, the differential quadrature method (DQM) is an efficient numerical technique, which was originated by Bellman to solve linear and nonlinear differential equations. ${ }^{48}$ The mathematical fundamentals and recent developments of the DQM, as well as its major applications in engineering, are discussed by Shu. ${ }^{49}$

A review of the literature shows that no attempt is made to utilize 3-D theory in the buckling and vibration analysis of stiffened composite conical shells whereas the stiffeners are treated as discrete elements. Hence, in this study, based on the 3-D theory, a hybrid LW-DQ method for vibration analysis of stiffened laminated conical shell with arbitrary boundary conditions subjected to axial load and external pressure is developed. It is important to note that the axial compressive load and external pressure must be a fraction of static critical global buckling load or pressure. The accuracy, convergence, and versatility of the algorithm are proved via different examples for both unstiffened and stiffened shells. Also, the effects of number of stiffeners, axial compressive load, and external pressure are demonstrated.

\section{PROBLEM FORMULATION}

\subsection{Geometrical Configuration}

The stiffened conical shell, as shown in Fig. 1, is considered to be thick or thin, laminated and composed of an arbitrary number of layers. In this figure, $L$ is the length, $h$ is the thickness, $\alpha$ is the half-cone angle, $r^{i}$ is the radius of the $i^{\text {th }}$ layer, and $U_{i}$ is the amplitude of the displacement in meridional $x$ direction. The reference surface of the conical shell is taken to be at its middle surface where an orthogonal co-ordinate system $(x, \theta, z)$ is fixed, and the displacement of the shell in the $x, \theta$ and $z$ directions are denoted by $u, v$, and $w$, respectively. The depth and width of the stiffeners are symbolized by $d_{s}, b_{s}$ or $d_{r}, b_{r}$. Subscripts $(s, r)$ indicate the stringer and ring stiffeners, respectively. The displacement from the outer surface of the shell to any point located on the stringer and ring are denoted by $z_{s}$ and $z_{r}$, respectively.

\subsection{Displacement Field in Layerwise Theory}

The displacement field for closed conical shells in the circumferential direction can be expanded as:

$$
\begin{aligned}
& u(x, \theta, z, t)=\sum_{n=1}^{\infty} U_{n}(x, z) \cos (n \theta+\omega t) ; \\
& v(x, \theta, z, t)=\sum_{n=1}^{\infty} V_{n}(x, z) \sin (n \theta+\omega t) ; \\
& w(x, \theta, z, t)=\sum_{n=1}^{\infty} W_{n}(x, z) \cos (n \theta+\omega t) ;
\end{aligned}
$$

where $n$ and $\omega$ represent the circumferential wave number and frequency, respectively.

In order to build a high degree of transverse discretization generality into the model, the layerwise laminate theory of Reddy is extended to be used here. ${ }^{3}$ In this theory, the variation of the displacements $U_{n}, V_{n}$, and $W_{n}$ through the thickness can be represented to a certain desired level of accuracy by simply increasing the order of the transverse interpolation polynomials as:

$$
\begin{aligned}
U_{n}(x, z) & =\sum_{n=1}^{N_{z}} U_{i n}(x) \psi_{i}(z) \\
V_{n}(x, z) & =\sum_{n=1}^{N_{z}} V_{i n}(x) \psi_{i}(z) \\
W_{n}(x, z) & =\sum_{n=1}^{N_{z}} W_{i n}(x) \psi_{i}(z)
\end{aligned}
$$

where $U_{i n}(x), V_{i n}(x)$, and $W_{i n}(x)$ denote the unknown displacement components at the node $i^{\text {th }}$ in the $x, \theta$ and $z$ direction, respectively; $N_{z}$ represents the number of nodes in the $z$-direction of the shell, which depends on the number of considered mathematical layers $N_{l}$ through the thickness and nodes per layer $N_{p l}$ in the thickness direction as $N_{z}=N_{l}\left(N_{p l}-1\right)+1$. Also, $\psi_{i}(z)$ is a piecewise continuous Lagrange interpolation function in terms of the thickness coordinate $z$ in the $i^{\text {th }}$ mathematical layer and is assumed to take the following form:

$$
\psi_{i}(z)= \begin{cases}0 & z \leq z_{i-1} \\ \frac{z-z_{i-1}}{h_{i-1}} & z_{i-1} \leq z \leq z_{i} \\ \frac{z_{i+1}-z}{h_{i}} & z_{i} \leq z \leq z_{i+1} \\ 0 & z \geq z_{i+1}\end{cases}
$$

where $h_{i}$ is the thickness of the $i^{\text {th }}$ layer and $z_{i}$ denotes the global thickness coordinate of the $i^{\text {th }}$ layer. 


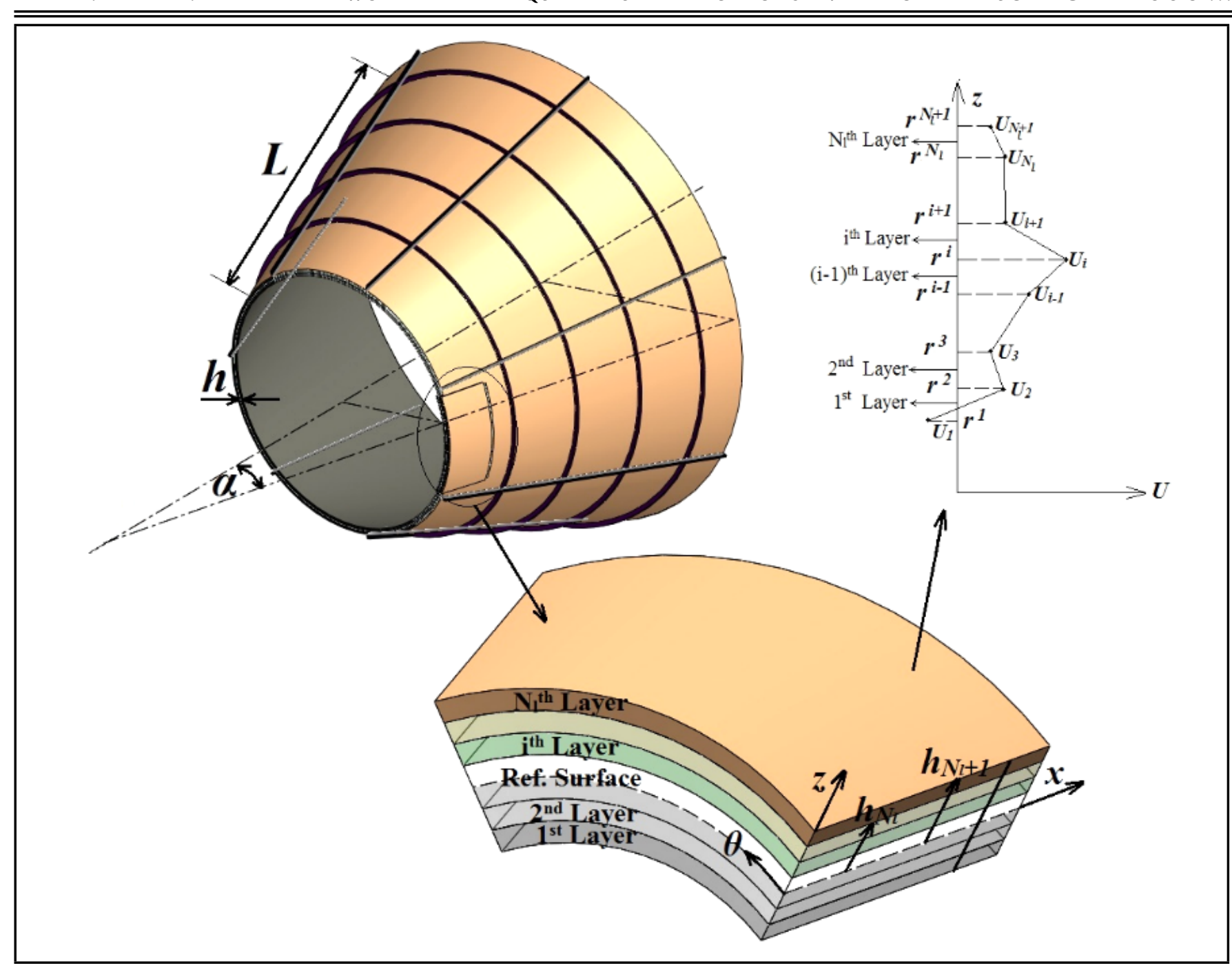

Figure 1. The Geometry of stiffened laminated conical shell structure.

\subsection{Total Energy}

The total energy of the stiffened conical shell under compressive load and external pressure can be written as:

$$
\Pi=T_{s h}+T_{r}+T_{s}-U_{s h}-U_{r}-U_{s}-W_{N_{a}}-W_{P}
$$

where $T_{s h}, T_{r}$, and $T_{s}$ denote the kinetic energy of the shell, rings and stringers, respectively, $U_{s h}, U_{r}$, and $U_{s}$ represent the strain energy of the shell, rings and stringers stiffeners, respectively, and $W_{N_{a}}, W_{P}$ are the potential energy due to axial compressive force per unit length and external pressure, respectively.

The kinetic energy expression of the shell can be written in the form:

$$
T_{s h}=\frac{1}{2} \int_{0}^{L} \int_{0}^{2 \pi} \int_{r_{i}}^{r_{o}} \rho\left[(\dot{u})^{2}+(\dot{v})^{2}+(\dot{w})^{2}\right] r d z d \theta d x
$$

where $r=r(x, z)=a+x \sin \alpha+z \cos \alpha, a$ is small radius of conical shell, $r_{i}$ is the inner radius, $r_{o}$ is the outer radius. The kinetic energy for the stringers and rings may be written as:

$$
\begin{aligned}
& T_{s}=\frac{1}{2} \rho_{s k} \sum_{k=1}^{N_{s}} \int_{0}^{L} \int_{A_{s k}}\left[\dot{u}^{2}+\dot{v}^{2}+\dot{w}^{2}\right] d A_{s k} d x \\
& T_{r}=\frac{1}{2} \rho_{r k} \sum_{k=1}^{N_{r}} \int_{0}^{2 \pi} \int_{A_{r k}}\left[\dot{u}^{2}+\dot{v}^{2}+\dot{w}^{2}\right]\left(r_{o}+\frac{d_{s}}{2}\right) d A_{r k} d \theta ;
\end{aligned}
$$

where $\rho_{s k}$ and $A_{s k}$ (or $\rho_{r k}$ and $A_{r k}$ ) are the density and cross section area of the $k^{\text {th }}$ stringer (or ring), respectively. The strain energy of the laminated composite conical shell is expressed as:

$$
U_{s h}=\frac{1}{2} \int_{0}^{L} \int_{0}^{2 \pi} \int_{r_{i}}^{r_{o}} \varepsilon^{T}[\bar{C}] \varepsilon r d z d \theta d x
$$

where $\varepsilon$ is the strain vector based on the three-dimensional theory of elasticity and it can be written as:

$$
\varepsilon^{T}=\left[\begin{array}{llllll}
\varepsilon_{x} & \varepsilon_{\theta} & \varepsilon_{z} & \gamma_{\theta z} & \gamma_{x z} & \gamma_{x \theta}
\end{array}\right]
$$


The linearized strain-displacement relations are as follows:

$$
\begin{gathered}
\varepsilon=D \cdot \chi ; \quad D=\left\{\begin{array}{ccc}
\frac{\partial}{\partial x} & 0 & 0 \\
\frac{S_{\alpha}}{r} & \frac{1}{r} \frac{\partial}{\partial \theta} & \frac{C_{\alpha}}{r} \\
0 & 0 & \frac{\partial}{\partial z} \\
0 & \frac{\partial}{\partial z}-\frac{C_{\alpha}}{r} & \frac{1}{r} \frac{\partial}{\partial \theta} \\
\frac{\partial}{\partial z} & 0 & \frac{\partial}{\partial x} \\
\frac{1}{r} \frac{\partial}{\partial \theta} & \frac{\partial}{\partial x} & \frac{\frac{S}{r}}{r}
\end{array}\right\} ; \\
\chi^{T}=\{u, v, w\} ; \quad S_{\alpha}=\sin \alpha ; \quad C_{\alpha}=\cos \alpha ;
\end{gathered}
$$

and $[\bar{C}]=[T]^{-1}[C][T]$ is the transformed stiffness matrix for a laminated shell, in which $[C]$ is the principle material stiffness matrix and $[T]$ is the transformation matrix. ${ }^{33}$

In order to maintain displacement compatibility between the stiffeners and the shell, a special transformation is used which includes coupling effects due to eccentric stiffener placement. It should also be noted that the displacements vary through the stiffeners' depth. Therefore, the displacement of a point at distance $z_{s}$ (or $z_{r}$ ) from the outer surface of shell for the stiffener can be expressed by shell displacement function as: ${ }^{21}$

$$
\begin{aligned}
& u_{s(\text { or } r)}=u_{N_{n z}}-z_{s(\text { or } r)} \frac{\partial w_{N_{n z}}}{\partial z} ; \\
& v_{s(\text { or } r)}=v_{N_{n z}}-\frac{z_{s(\text { or } r)}}{r_{o}} \frac{\partial w_{N_{n z}}}{\partial \theta} ; \\
& w_{s(\text { or } r)}=w_{N_{n z}} ;
\end{aligned}
$$

where $u_{N_{n z}}, v_{N_{n z}}$, and $w_{N_{n z}}$ are the displacements of the outer layer of the shell. The strain of the stringers in the meridional direction and the strain of the rings in the circumferential direction are defined as:

$$
\begin{gathered}
\varepsilon_{s x}=\frac{\partial u_{N_{n z}}}{\partial x}-z_{s} \frac{\partial^{2} w_{N_{n z}}}{\partial x^{2}} \\
\varepsilon_{r \theta}=\frac{1}{r_{o}}\left(u_{N_{n z}} \sin \alpha-z_{r} \frac{\partial w_{N_{n z}}}{\partial z} \sin \alpha+\frac{\partial v_{N_{n z}}}{\partial \theta}-\right. \\
\left.\frac{z_{r}}{r_{o u}} \frac{\partial^{2} w_{N_{n z}}}{\partial \theta^{2}}+w_{N_{n z}} \cos \alpha\right) .
\end{gathered}
$$

Using the discrete stiffener theory, the strain energies of the stringer and ring can be written as: ${ }^{28}$

$$
\begin{aligned}
U_{s}= & \frac{1}{2} \sum_{k=1}^{N_{s}} E_{s k} \int_{0}^{L} \int_{A_{s k}} \varepsilon_{s x}^{2} d A_{s k} d x+ \\
& \frac{1}{2} \sum_{k=1}^{N_{s}} G_{s k} J_{s k} \int_{0}^{L}\left[\frac{1}{r_{o}^{2}} \frac{\partial^{2} w_{s}}{\partial x \partial \theta}-\frac{2 \sin \alpha}{r_{o}^{2}} \frac{\partial w}{\partial \theta}-\right. \\
& \left.\frac{\cos \alpha}{r_{o}} \frac{\partial v}{\partial x}+\frac{2 \sin \alpha \cos \alpha}{r_{o}^{2}} v\right]^{2} d x \\
U_{r}= & \frac{1}{2} \sum_{k=1}^{N_{r}} E_{r k} \int_{0}^{2 \pi} \int_{A_{r k}} \varepsilon_{r \theta}^{2} d A_{r k} r_{o k} d \theta+ \\
& \frac{1}{2} \sum_{k=1}^{N_{r}} G_{r k} J_{r k} \int_{0}^{2 \pi}\left[\frac{1}{r_{o k}^{2}}\left(\frac{\partial^{2} w_{s}}{\partial \theta \partial x}\right)^{2}\right]\left(r_{o k}+\frac{d_{r}}{2}\right) d \theta
\end{aligned}
$$

where $G_{s k} J_{s k}\left(G_{r k} J_{r k}\right)$ and $A_{s k}\left(A_{r k}\right)$ are the torsional stiffness and the cross sectional area of the $k^{\text {th }}$ stringer (ring), respectively, and $N_{s}\left(N_{r}\right)$ is the number of stringers (rings).
Besides, the work carried out on the shell due to axial forced is described as

$$
\begin{aligned}
W_{N_{a}}=\frac{1}{2} \int_{0}^{L} \int_{0}^{2 \pi} N_{a}\left(\frac{\partial w}{\partial x}\right)^{2} r_{o} d \theta d x ; \\
W_{P}=\frac{1}{2} \int_{0}^{L} \int_{0}^{2 \pi} \frac{P}{r_{o}^{2}}\left[\left(v \cos \alpha-\frac{\partial w}{\partial \theta}\right)^{2}+\right. \\
\\
\left.\left(\frac{\partial v}{\partial \theta}+w \cos \alpha\right)^{2}\right] r_{o} d \theta d x .
\end{aligned}
$$

\subsection{Governing Equations of Motion}

The governing equations of motion can be derived by using Hamilton's principle as:

$$
\begin{gathered}
\int_{t_{0}}^{t_{1}} \delta(\Pi) d t=\int_{t_{0}}^{t_{1}}\left(\delta T_{s h}+\delta T_{r}+\delta T_{s}-\delta U_{s h}-\delta U_{r}-\delta U_{s}-\right. \\
\left.\delta W_{N_{a}}-\delta W_{P}\right) d t=0 .
\end{gathered}
$$

Substituting Eqs. (5-8) and (15-16) into Eq. (17), the equations of motion and the related boundary conditions for global buckling analysis of arbitrary stiffened laminated conical shell can be derived by Eqs. (18-20), where $S_{\alpha}=\sin \alpha, C_{\alpha}=$ $\cos \alpha$ and $\delta$ is Kronecker's delta.

Geometrical and natural boundary conditions at both ends are derived as:

$$
\begin{aligned}
& \text { Either }\left.U_{i n}\right|_{x=0, L}=0 \\
& \text { or } \quad N_{x}^{i n}=\pi\left[\left(A_{12}^{i j} \cos \alpha+E_{13}^{j i}\right) W_{j n}+n A_{12}^{i j} V_{j n}+\right. \\
& \left.\left(B_{11}^{i j} \frac{\partial}{\partial x}+A_{12}^{i j} \sin \alpha\right) U_{j n}\right]\left.\right|_{x=0, L}=0 ;
\end{aligned}
$$

Either $\left.\quad V_{i n}\right|_{x=0, L}=0$

$$
\begin{array}{r}
\text { or } \quad M_{x \theta}^{i n}=\pi\left[-n A_{66}^{i j} U_{j n}+B_{66}^{i j} \frac{\partial V_{j n}}{\partial x}-\right. \\
\left.\sin \alpha A_{66}^{i j} W_{j n}\right]\left.\right|_{x=0, L}=0 ;
\end{array}
$$

Either $\left.W_{i n}\right|_{x=0, L}=0$

$$
\text { or } \quad M_{x z}^{i n}=\left.\pi\left[E_{55}^{j i} U_{j n}+B_{55}^{i j} \frac{\partial W_{j n}}{\partial x}\right]\right|_{x=0, L}=0
$$

where:

$$
\begin{array}{rlrl}
A_{k l}^{i j} & =\int_{r_{i}}^{r_{o}} C_{k l} \psi_{i} \psi_{j} d r ; & B_{k l}^{i j} & =\int_{r_{i}}^{r_{o}} C_{k l} \psi_{i} \psi_{j} r d r ; \\
C_{k l}^{i j} & =\int_{r_{i}}^{r_{o}} C_{k l} \frac{\psi_{i} \psi_{j}}{r} d r ; & D_{k l}^{i j} & =\int_{r_{i}}^{r_{o}} C_{k l} \psi_{i}^{\prime} \psi_{j} d r ; \\
E_{k l}^{i j} & =\int_{r_{i}}^{r_{o}} C_{k l} \psi_{i}^{\prime} \psi_{j} r d r ; & F_{k l}^{i j} & =\int_{r_{i}}^{r_{o}} C_{k l} \psi_{i}^{\prime} \psi_{j}^{\prime} r d r ; \\
G^{i j} & =\int_{r_{i}}^{r_{o}} \rho \psi_{i} \psi_{j} r d r . &
\end{array}
$$




$$
\begin{aligned}
\delta U_{i n}: \pi & \left\{\left(F_{55}^{i j}+n^{2} C_{66}^{i j}+S_{\alpha}^{2} C_{22}^{i j}-B_{11}^{i j} \frac{\partial^{2}}{\partial x^{2}}\right) U_{j n}+G^{i j} \frac{\partial^{2} U_{j n}}{\partial t^{2}}-\left(n A_{12}^{i j}+n A_{66}^{i j}\right) \frac{\partial}{\partial x} V_{j n}+n S_{\alpha}\left(C_{22}^{i j}+C_{66}^{i j}\right) V_{j n}-\right. \\
& \left(C_{\alpha} A_{12}^{i j}+E_{13}^{j i}-E_{55}^{i j}\right) \frac{\partial}{\partial x} W_{j n}+\left(S_{\alpha} C_{\alpha} C_{22}^{i j}+S_{\alpha} D_{23}^{j i}\right) W_{j n}+\frac{\delta_{j N_{n z}} E_{s} A_{s} N_{s}}{\pi}\left(-\frac{\partial^{2} U_{j n}}{\partial x^{2}}+\frac{d_{s}}{2} \frac{\partial^{3} W_{j n}}{\partial x^{3}}\right)+ \\
& \delta_{j N_{n z}} E_{r} A_{r} S_{\alpha}^{2} \sum_{k=1}^{N_{r}} \frac{\delta\left(x-x_{k}\right)}{r_{o k}} U_{j n}+\delta_{j N_{n z}} E_{r} A_{r} n S_{\alpha} \sum_{k=1}^{N_{r}} \frac{\delta\left(x-x_{k}\right)}{r_{o k}} V_{j n}+ \\
& \delta_{j N_{n z}} E_{r} A_{r} S_{\alpha} \sum_{k=1}^{N_{r}}\left(\frac{n^{2} d_{r}}{2 r_{o k}}-\frac{d_{r} S_{\alpha}}{2} \frac{\partial}{\partial x}+C_{\alpha}\right) \delta\left(x-x_{k}\right) W_{j n}+\frac{\delta_{j N_{n z}} N_{s} A_{s} \rho_{s}}{\pi} \frac{\partial^{2} U_{j n}}{\partial t^{2}}- \\
& \left.\frac{\delta_{j N_{n z}} N_{s} A_{s} \rho_{s}}{\pi} \frac{d_{s}}{2} \frac{\partial^{3} W_{j n}}{\partial x \partial t^{2}}+\frac{\delta_{j N_{n z}} A_{r} \rho_{r}}{\pi} \sum_{k=1}^{N_{r}}\left(\frac{\partial^{2}}{\partial t^{2}}\right) r_{o k} \delta\left(x-x_{k}\right) U_{j n}-\frac{\delta_{j N_{n z}} A_{r} \rho_{r}}{\pi} \sum_{k=1}^{N_{r}} r_{o k} \delta\left(x-x_{k}\right) W_{j n}\right\}=0 ;
\end{aligned}
$$

$$
\begin{aligned}
\delta V_{i n}: \pi & \left\{n\left(A_{12}^{i j}+A_{66}^{i j}\right) \frac{\partial}{\partial x} U_{j n}+n\left[D_{23}^{j i}+\left(C_{44}^{i j}+C_{22}^{i j}\right) C_{\alpha}-D_{44}^{i j}\right] W_{j n}+\right. \\
& {\left[n^{2} C_{22}^{i j}+F_{44}^{i j}-\left(D_{44}^{i j}+D_{44}^{j i}\right) C_{\alpha}+C_{44}^{i j} C_{\alpha}^{2}-B_{66}^{i j} \frac{\partial^{2}}{\partial x^{2}}+C_{66}^{i j} S_{\alpha}^{2}\right] V_{j n}+G^{i j} \frac{\partial^{2} V_{j n}}{\partial t^{2}}+} \\
& \frac{\delta_{j N_{n z}} G_{s} J_{s} N_{s}}{\pi}\left(-\frac{C_{\alpha}^{2}}{r_{o}^{2}} \frac{\partial^{2} V_{j n}}{\partial x^{2}}+\frac{4 S_{\alpha}^{2} C_{\alpha}^{2}}{r_{o}^{4}} V_{j n}\right)+\frac{\delta_{j N_{n z}} G_{s} J_{s} N_{s}}{\pi}\left(-\frac{n C_{\alpha}}{r_{o}^{2}} \frac{\partial^{2} W_{j n}}{\partial x^{2}}+\frac{4 n S_{\alpha}^{2} C_{\alpha}}{r_{o}^{4}} W_{j n}\right)+ \\
& \delta_{j N_{n z}} E_{r} A_{r} n S_{\alpha} \sum_{k=1}^{N_{r}} \frac{\delta\left(x-x_{k}\right)}{r_{o k}} U_{j n}+\delta_{j N_{n z}} E_{r} A_{r} n^{2} \sum_{k=1}^{N_{r}} \frac{\delta\left(x-x_{k}\right)}{r_{o k}} V_{j n}+ \\
& \delta_{j N_{n z}} A_{r}\left[E_{r} n \sum_{k=1}^{N_{r}}\left(\frac{n^{2} d_{r}}{2 r_{o k}}-\frac{d_{r} S_{\alpha}}{2} \frac{\partial}{\partial x}+C_{\alpha}\right) \delta\left(x-x_{k}\right) W_{j n}\right]+\frac{\delta_{j N_{n z}} N_{s} A_{s} \rho_{s}}{\pi} \frac{\partial^{2} V_{j n}}{\partial t^{2}}-\frac{\delta_{j N_{n z}} N_{s} A_{s} \rho_{s}}{\pi}- \\
& \left.\frac{d_{s} n}{2 r_{o}} \frac{\partial^{2} W_{j n}}{\partial t^{2}}-\frac{\delta_{j N_{n z}} A_{r} \rho_{r}}{\pi} \sum_{k=1}^{N_{r}}\left(-\frac{\partial^{2}}{\partial t^{2}}\right) r_{o k} \delta\left(x-x_{k}\right) V_{j n}-\frac{\delta_{j N_{n z}} A_{r} \rho_{r}}{\pi} \sum_{k=1}^{N_{r}}\left(\frac{d_{r} n}{2 r_{o}} \frac{\partial^{2}}{\partial t^{2}}\right) r_{o k} \delta\left(x-x_{k}\right) W_{j n}\right\}=0
\end{aligned}
$$

$$
\begin{aligned}
& \delta W_{i n}: \pi\left\{\left(C_{\alpha} A_{12}^{i j}+E_{13}^{i j}-E_{55}^{i j}\right) \frac{\partial}{\partial x} U_{j n}+\left(S_{\alpha} C_{\alpha} C_{22}^{i j}+S_{\alpha} D_{23}^{i j}\right) U_{j n}+n\left[D_{23}^{j i}+\left(C_{44}^{i j}+C_{22}^{i j}\right) C_{\alpha}-D_{44}^{j i}\right] V_{j n}+\right. \\
& {\left[C_{22}^{i j} C_{\alpha}^{2}+\left(D_{23}^{j i}+D_{23}^{i j}\right) C_{\alpha}+F_{33}^{i j}+n^{2} C_{44}^{i j}-B_{55}^{i j} \frac{\partial^{2}}{\partial x^{2}}+N_{a} r_{o} \frac{\partial^{2}}{\partial x^{2}}\right] W_{j n}+G^{i j} \frac{\partial^{2} W_{j n}}{\partial t^{2}}+} \\
& \frac{\delta_{j N_{n z}} E_{s} A_{s} N_{s}}{\pi}\left(-\frac{d_{s}}{2} \frac{\partial^{3} U_{j n}}{\partial x^{3}}\right)+\frac{\delta_{j N_{n z}} G_{s} J_{s} N_{s}}{\pi}\left(-\frac{n C_{\alpha}}{r_{o}^{2}} \frac{\partial^{2} V_{j n}}{\partial x^{2}}+\frac{4 n S_{\alpha}^{2} C_{\alpha}}{r_{o}^{4}} V_{j n}\right)+ \\
& \frac{\delta_{j N_{n z}} E_{s} I_{s} N_{s}}{\pi}\left(\frac{\partial^{4} W_{j n}}{\partial x^{4}}\right)+\frac{\delta_{j N_{n z}} G_{s} J_{s} N_{s}}{\pi}\left(-\frac{n^{2}}{r_{o}^{2}} \frac{\partial^{2} W_{j n}}{\partial x^{2}}+\frac{4 n^{2} S_{\alpha}^{2}}{r_{o}^{4}} W_{j n}\right)+ \\
& \delta_{j N_{n z}} E_{r} A_{r} d_{r}\left[S_{\alpha} \sum_{k=1}^{N_{r}}\left(\frac{n^{2}}{2 r_{o k}}+\frac{S_{\alpha}}{2} \frac{\partial}{\partial x}+\frac{C_{\alpha}}{d_{r}}\right) \delta\left(x-x_{k}\right) U_{j n}+n \sum_{k=1}^{N_{r}}\left(\frac{n^{2}}{2 r_{o k}}+\frac{S_{\alpha}}{2} \frac{\partial}{\partial x}+\frac{C_{\alpha}}{d_{r}}\right) \delta\left(x-x_{k}\right) V_{j n}\right]+ \\
& \delta_{j N_{n z}}\left[E_{r} \sum_{k=1}^{N_{r}}\left(\frac{I_{r}}{r_{o k}^{3}} n^{4}-\frac{I_{r} S_{\alpha}^{2}}{r_{o k}} \frac{\partial^{2}}{\partial x^{2}}+\frac{A_{r} C_{\alpha}^{2}}{r_{o k}}+\frac{A_{r} d_{r} n^{2} C_{\alpha}}{r_{o k}}\right) \delta\left(x-x_{k}\right)-G_{r} J_{r} n^{2} \sum_{k=1}^{N_{r}}\left(\frac{\delta\left(x-x_{k}\right)}{r_{o k}} \frac{\partial^{2}}{\partial x^{2}}\right)\right] W_{j n}+ \\
& \frac{\delta_{j N_{n z}} N_{s} A_{s} \rho_{s} d_{s}}{2 \pi} \frac{\partial^{3} U_{j n}}{\partial x \partial t^{2}}+\frac{\delta_{j N_{n z}} N_{s} A_{s} \rho_{s} d_{s} n}{2 r_{o} \pi} \frac{\partial^{2} V_{j n}}{\partial t^{2}}-\frac{\delta_{j N_{n z}} N_{s} \rho_{s}}{\pi}\left[I_{s}\left(\frac{\partial^{4}}{\partial x^{2} \partial t^{2}}-\frac{n^{2}}{r_{o}^{2}} \frac{\partial^{2}}{\partial t^{2}}\right)-A_{s} \frac{\partial^{2}}{\partial t^{2}}\right] W_{j n}+ \\
& \frac{\delta_{j N_{n z}} A_{r} \rho_{r}}{\pi} \sum_{k=1}^{N_{r}}\left(\frac{d_{r}}{2} \frac{\partial^{3}}{\partial x \partial t^{2}}\right) r_{o k} \delta\left(x-x_{k}\right) U_{j n}+\frac{\delta_{j N_{n z}} A_{r} \rho_{r}}{\pi} \sum_{k=1}^{N_{r}}\left(\frac{d_{r} n}{2 r_{o}} \frac{\partial^{2}}{\partial t^{2}}\right) r_{o k} \delta\left(x-x_{k}\right) V_{j n}- \\
& \left.\frac{\delta_{j N_{n z}} \rho_{r}}{\pi} \sum_{k=1}^{N_{r}}\left(I_{r} \frac{\partial^{4}}{\partial x^{2} \partial t^{2}}-\frac{I_{r} n^{2}}{r_{o}^{2}} \frac{\partial^{2}}{\partial t^{2}}-A_{r} \frac{\partial^{2}}{\partial t^{2}}\right) r_{o k} \delta\left(x-x_{k}\right) W_{j n}\right\}=0 .
\end{aligned}
$$


Table 1. Mechanical properties of the material of the shell.

\begin{tabular}{|c|c|c|c|c|}
\hline & Modulus of Elasticity $(\mathrm{GPa})$ & Poisson's Ratio & Modulus of Rigidity $(\mathrm{GPa})$ & Density $\left(\mathrm{kg} / \mathrm{m}^{3}\right)$ \\
\hline Isotropic & $E=7.6$ & $\nu=0.3$ & $G=2.9$ & $\rho=1600$ \\
\hline \multirow{2}{*}{ Orthotropic } & $E_{22}=E_{33}=7.6$ & $\nu_{12}=0.26$ & $G_{12}=G_{23}=4.1$ & $\rho=1643$ \\
& $E_{11}=2.5 E_{22}$ & $\nu_{13}=\nu_{23}=0.2$ & $G_{13}=2$ & \multirow{2}{*}{$\begin{array}{c}2 \\
\end{array}$} \\
\hline
\end{tabular}

Table 2. The geometrical parameters and material properties of the stiffeners.

\begin{tabular}{|c|c|c|}
\hline Stiffener Type & Stringer & Ring \\
\hline Depth $(\mathrm{mm})$ & 8 & 8 \\
Width $(\mathrm{mm})$ & 2 & 2 \\
$E(\mathrm{GPa})$ & 70 & 70 \\
$\nu$ & 0.3 & 0.3 \\
$\rho\left(\mathrm{kg} / \mathrm{m}^{3}\right)$ & 2707 & 2707 \\
\hline
\end{tabular}

\subsection{Differential Quadrature Discretization}

The DQ method is a numerical method with flexibility given for the arrangement of the grid points in the domain of interest. It also possesses higher-order interpolation characteristics. In order to use the DQ method to discretize the governing equations in the meridional direction $x$, each nodal surface is discretized into a set of $N_{x}$ grid points in this direction. ${ }^{43}$ Using the DQ-discretization rules at each domain and boundary condition grid point, the equations of motion as well as the boundary condition equations are transformed into a set of algebraic equations. The derivatives of a function $f\left(x_{i}\right)$ as an example, at a point $x_{i}$ are expressed as:

$$
\left.\frac{\partial^{s} f(x)}{\partial x^{s}}\right|_{x=x_{i}}=\sum_{j=1}^{N_{x}} C_{i j}^{s} f\left(x_{i}\right), \quad i=1,2, \ldots, N_{x}
$$

where $f$ can be taken $U_{i n}, V_{i n}$, and $W_{i n}$ and $C_{i j}^{s}$ are the respective weighting coefficients related to the $s^{\text {th }}$-order derivative. In this paper, one of the following boundary conditions or some combinations of them are considered as: a) Clamped $U_{i n}=V_{i n}=W_{i n}=0$ and b) Simply supported $V_{i n}=W_{i n}=$ $N_{i n}^{x}=0$.

Thus, the whole system of differential equation has been discretized and the global assembling leads to the following set of linear algebraic equations:

$$
\left\{[M] \omega^{2}\right\}\{d\}+\{[G] \omega\}\{d\}+\left[K_{d d}\right]\{d\}+\left[K_{d b}\right]\{b\}=0 .
$$

In the Eq. (26), vectors $\{d\}$ and $\{b\}$ with dimensions $3 N_{z}\left(N_{x}-2\right)$ and $6 N_{z}$, denote the unknowns at the sampling points in the interior domain and those on the boundary. The dimension of $\left[K_{d d}\right]$ is $N^{*} \times N^{*}\left(N^{*}=3 N_{z}\left(N_{x}-2\right)\right)$ and dimension of $\left[K_{d b}\right]$ is $N^{*} \times 6 N_{z}$.

In a similar manner, the discretized form of the boundary conditions becomes:

$$
\left[K_{b d}\right]\{d\}+\left[K_{b b}\right]\{b\}=0 ;
$$

the dimension of $\left[K_{b d}\right]$ is $6 N_{z} \times N^{*}$ and dimension of $\left[K_{b b}\right]$ is $6 N_{z} \times 6 N_{z}$.

Using Eq. (27) to eliminate the boundary degrees of freedom $\{b\}$ from Eq. (26), it can be concluded as:

$$
\begin{aligned}
\left\{[M] \omega^{2}\right\}\{d\} & +\{[G] \omega\}\{d\}+ \\
& \underbrace{\left\{\left[K_{d d}\right]-\left[K_{d b}\right]\left[K_{b b}\right]^{-1}\left[K_{b d}\right]\right\}}_{K}\{d\}=0 .
\end{aligned}
$$

For a given frequency, it can be transformed equivalently into a standard form of eigenvalue equation as:

$$
(\underbrace{\left[\begin{array}{cc}
0 & I \\
-K & -G
\end{array}\right]}_{A^{*}}-\underbrace{\left[\begin{array}{cc}
I & 0 \\
0 & M
\end{array}\right]}_{B^{*}} \omega)\left\{\begin{array}{c}
d \\
\omega d
\end{array}\right\}=0
$$

where $I$ is a $N^{*} \times N^{*}$ identity matrix.

Using a conventional eigenvalue approach, the standard eigenvalue Eq. (29) can be solved, and $2 N^{*}$ eigenvalues are obtained. From these eigenvalues, the two eigenvalues for which the absolute of real values are the smallest are chosen. One of these eigenvalues is negative and corresponds to backward wave, and the other one is positive and corresponds to forward wave. To achieve the static critical global buckling load or pressure, the global buckling differential equations can be obtained by neglecting the terms involving $\omega$ in Eq. (28). The resulting equation has nontrivial solutions only when the determinant of its matrix is zero. The problem of determining the buckling load for identified values of $n$ has therefore been reduced to that of finding the roots of the characteristic equation as follows:

$$
\begin{aligned}
a_{0} N_{a}^{N_{x}\left(N_{x}-2\right)} & +a_{1} N_{a}^{N_{x}\left(N_{x}-2\right)-1}+\ldots+ \\
& a_{N_{x}\left(N_{x}-2\right)-1} N_{a}+a_{N_{x}\left(N_{x}-2\right)}=0
\end{aligned}
$$

or

$$
\begin{aligned}
& a_{0} P^{2 N_{x}\left(N_{x}-2\right)}+a_{1} P^{2 N_{x}\left(N_{x}-2\right)-1}+\ldots+ \\
& a_{2 N_{x}\left(N_{x}-2\right)-1} P+a_{2 N_{x}\left(N_{x}-2\right)}=0 ;
\end{aligned}
$$

where $a_{i}$ are known functions of the coefficients $K_{i j}$. The critical global buckling load or pressure will then be the smallest value of $N_{a}$ or $P$ corresponding to integer values of $n$.

\section{NUMERICAL RESULTS AND DISCUSSION}

In the presentation of results shown in figures, three boundary conditions are considered here for the stiffened conical shell. These boundary conditions are the fully clamped (Cs$\mathrm{Cl}$ ), fully simply supported ( $\mathrm{Ss}-\mathrm{Sl}$ ), and simply supported at small edge-clamped at large edge (Ss-Cl). In addition, all layers are assumed to be of the same thickness and material, and material properties of the shell used in the present study are listed in Table 1. The geometrical dimensions and material properties of the stiffeners used in the present study are given in Table 2.

\subsection{Convergence Checking}

The convergence behaviours of the method for conical shells with two different values of thicknesses for cone angle $15^{\circ}$ are presented in Fig. 2. From this figure, regardless of the thickness, good convergence is achieved when the number of grid points (NGP) exceeds 10 .

Also, the convergence behaviours of the critical buckling load for stiffened cross-ply $\left[0^{\circ} / 90^{\circ} / 0^{\circ}\right]$ laminated cylindrical 


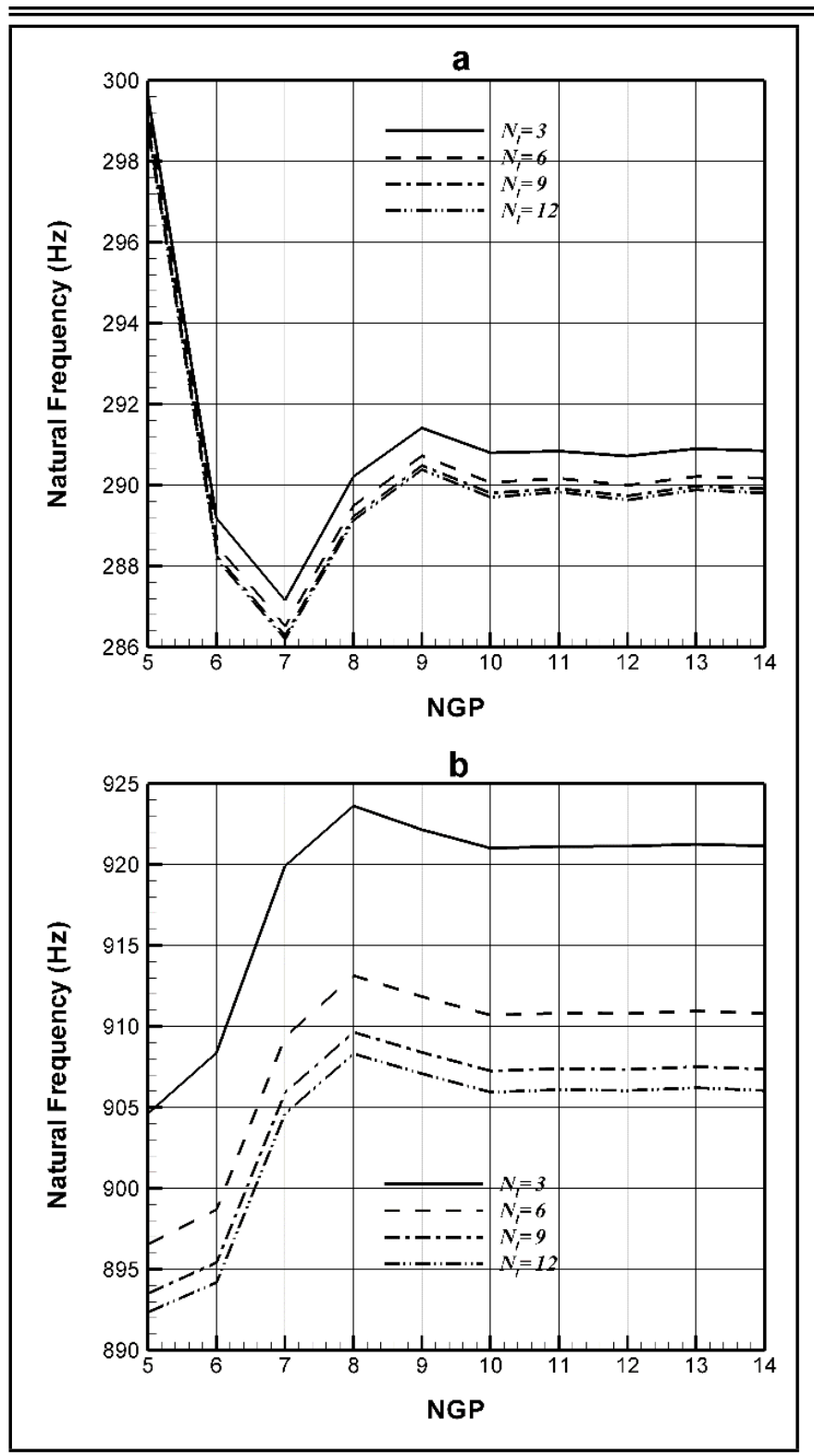

Figure 2. Convergence behaviour of the natural frequency of laminated conical shell with Ss-Sl boundary condition, (a) $h=50 \mathrm{~mm}$, (b) $h=250 \mathrm{~mm}$ $\left(L=2 \mathrm{~m}, a=0.5 \mathrm{~m}, n=5, \alpha=15^{\circ},\left[0^{\circ} / 90^{\circ} / 0^{\circ}\right]\right)$.

shell with Ss-Sl boundary condition are presented in Table 3. In addition, the results are compared with those of LW-exact solutions. The convergence behaviours against NGP along the meridional direction were examined. The results are performed for four different values of length of the shell. For all configurations, it can be deduced that the critical buckling load is occurring in mode $n=11$. However, the number of meridional mode with occurrence of the critical buckling load increases when the length of the shell is enhanced. For example, the buckling load occurred at $m=2$ for $L=0.5$, and at $m=4$ for $L=1.0$. Therefore, more NGP are needed for true prospecting of the displacement field along the meridional direction and the convergence is delayed.

In addition, the convergence behaviours of the method in obtaining axial buckling load for unstiffened conical shell with three different values of half-cone angles are presented in Fig. 3 . It is clearly found that the results are rapidly converged and the trend of convergence for conical shell with different cone angles behaves in the same way.
Table 3. Convergence behaviour of the buckling load of laminated cylindrical shell with Ss-Sl boundary condition ( $a=0.5 \mathrm{~m}, h=3 \mathrm{~mm}$, Carbon-Epoxy, $\left.\left[0^{\circ} / 90^{\circ} / 0^{\circ}\right]\right)$.

\begin{tabular}{|r|cccc|}
\hline & $L=0.25 \mathrm{~m}$ & $L=0.5 \mathrm{~m}$ & $L=0.75 \mathrm{~m}$ & $L=1.0 \mathrm{~m}$ \\
\hline LW-Ex. & $0.243 \mathrm{e} 6(1,11)$ & $0.243 \mathrm{e} 6(2,11)$ & $0.243 \mathrm{e} 6(3,11)$ & $0.243 \mathrm{e} 6(4,11)$ \\
\hline NGP & & & & \\
6 & $0.239 \mathrm{e} 6(11)$ & $0.231 \mathrm{e} 6(11)$ & $0.254 \mathrm{e} 6(11)$ & $0.316 \mathrm{e} 6(11)$ \\
7 & $0.244 \mathrm{e} 6(11)$ & $0.235 \mathrm{e} 6(11)$ & $0.227 \mathrm{e} 6(11)$ & $0.240 \mathrm{e} 6(11)$ \\
8 & $0.244 \mathrm{e} 6(11)$ & $0.246 \mathrm{e} 6(11)$ & $0.227 \mathrm{e} 6(11)$ & $0.222 \mathrm{e} 6(11)$ \\
9 & $0.244 \mathrm{e} 6(11)$ & $0.254 \mathrm{e} 6(11)$ & $0.231 \mathrm{e} 6(11)$ & $0.217 \mathrm{e} 6(11)$ \\
LW-DQ 10 & & $0.243 \mathrm{e} 6(11)$ & $0.238 \mathrm{e} 6(11)$ & $0.224 \mathrm{e} 6(11)$ \\
11 & & $0.243 \mathrm{e} 6(11)$ & $0.242 \mathrm{e} 6(11)$ & $0.230 \mathrm{e} 6(11)$ \\
12 & & & $0.242 \mathrm{e} 6(11)$ & $0.232 \mathrm{e} 6(11)$ \\
13 & & & $0.242 \mathrm{e} 6(11)$ & $0.235 \mathrm{e} 6(11)$ \\
14 & & & & $0.244 \mathrm{e} 6(11)$ \\
15 & & & & $0.244 \mathrm{e} 6(11)$ \\
\hline
\end{tabular}

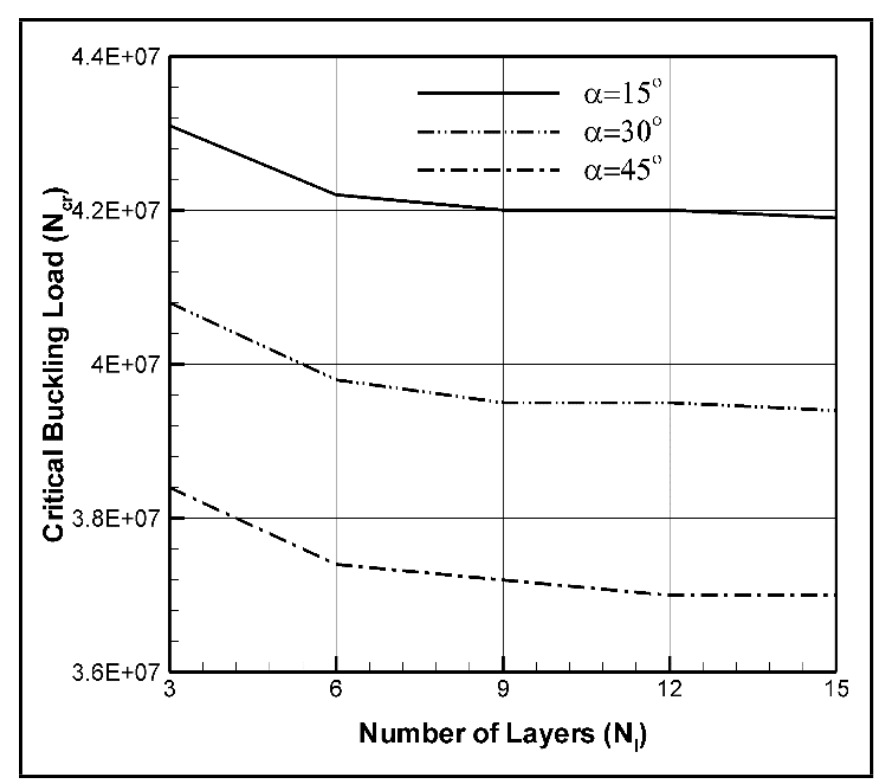

Figure 3. Convergence behaviour of the buckling axial load of laminated conical shell with Cs-Cl boundary condition $(L=0.25 \mathrm{~m}, a=0.5 \mathrm{~m}$, $\left.h=30 \mathrm{~mm}, \alpha=15^{\circ},\left[0^{\circ} / 90^{\circ} / 0^{\circ}\right]\right)$.

\subsection{Validation}

In order to validate the results, firstly, the formulation is customized for an unstiffened composite cylindrical shell with different boundary conditions. The results of the nondimensional buckling load $\bar{N}=N_{x} L^{2} / 100 h^{3} E_{2}$ of thick cylindrical shells, listed in Table 4, are compared with the work done by Khdeir et al. ${ }^{35}$ which considers different theories of HSDT, FSDT, and CST for the composite cylindrical shells. The trend of the results listed in this table indicates the accuracy of the present work as it is based on 3D theory of elasticity.

The second comparison, as depicted in Fig. 4, is for a laminated conical shell with fully simply supported boundary condition by present formulations and those of exact method obtained by Shadmehri et al. ${ }^{12}$ It can be seen that the two sets of frequencies are very close to each other, but the present results, particularly for high cone angles, are a bit lower than those found in Shadmehri et al. ${ }^{12}$ This may be due to difference of shell theories. The first order shear deformation theory has been employed in Shadmehri et al. ${ }^{12}$ In this paper, the 3-D shell theory is used.

In Fig. 5, an additional comparison is made between the theoretically and experimentally produced natural frequencies of orthogonal stiffened conical shell by Crenwelge and Muster ${ }^{26}$ and Daneshjou et al. ${ }^{34}$ and the theory proposed here. The 
Table 4. Dimensionless critical buckling load $\bar{N}=N_{x} L^{2} / 100 h^{3} E_{2}$ for cross-ply laminated cylindrical shell under various boundary conditions. $(L / R=1, R / h=10)$.

\begin{tabular}{||ccccc||}
\hline Stacking Sequence & Theory & SS & SC & CC \\
\hline & CST $^{35}$ & 0.1817 & 0.2286 & 0.3310 \\
{$\left[0^{\circ} / 90^{\circ}\right]$} & FSDT $^{35}$ & 0.1670 & 0.1969 & 0.2508 \\
& HSDT $^{35}$ & 0.1687 & 0.2011 & 0.2617 \\
& Present (LW-DQ) & 0.1485 & 0.1729 & 0.2209 \\
\hline & CST $^{35}$ & 0.4186 & 0.7457 & 1.3631 \\
{$\left[0^{\circ} / 90^{\circ} / 0^{\circ}\right]$} & FSDT $^{35}$ & 0.2813 & 0.3452 & 0.4197 \\
& HSDT $^{35}$ & 0.2794 & 0.3434 & 0.4213 \\
& Present (LW-DQ) $^{35}$ & 0.2751 & 0.3342 & 0.3997 \\
\hline & CST $^{35}$ & 0.3395 & 0.5000 & 0.8122 \\
& FSDT $^{35}$ & 0.2898 & 0.3382 & 0.3967 \\
& HSDT $^{35}$ & 0.2896 & 0.3388 & 0.4037 \\
& Present (LW-DQ) & 0.2871 & 0.3309 & 0.3892 \\
\hline
\end{tabular}

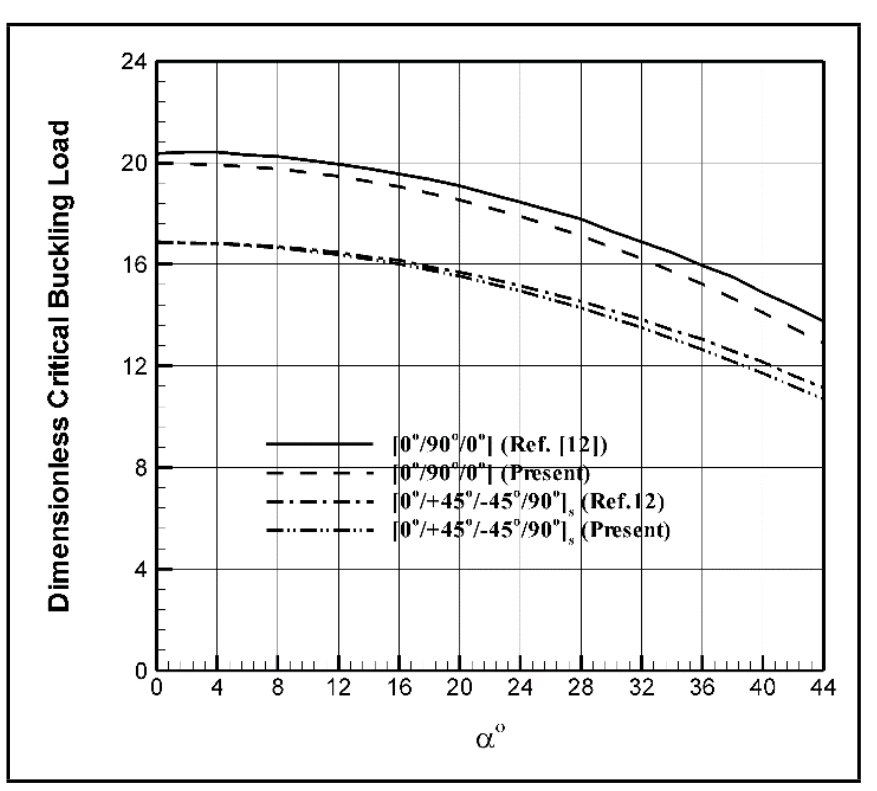

Figure 4. Variation of the dimensionless critical buckling load $\bar{N}=$ $N_{x} L^{2} / h^{3} E_{22}$ with the cone angle. Comparison between results of present study and those reported in Shadmehri et al. ${ }^{12}(b / h=100, b / L=10)$.

present theory estimates more accurate results than the smearing method, since the former assumes the stiffeners as discrete elements while Crenwelge and Muster ${ }^{26}$ consider the properties of the stiffeners averaged throughout the shell. Also, comparing the present results with those reported in Daneshjou et al. ${ }^{34}$ reveals a satisfactory agreement. The slight divergence in high modes $(n>6)$ is attributed to different theories among these two researches. The classic shell theory (CLT) has been employed in Daneshjou et al. ${ }^{34}$ In this paper, the 3-D shell theory is used. Moreover, the present theory is in good agreement with the experimental results. In higher modes $(n>8)$ the difference is occurred between the present theory and the experimental results. This seems to occur because the shell stiffened with widely separated stiffeners is less rigid upon bending than expected before. On the other hand, in present method the stiffener is expected to be moved with structure as an integral part which may be different from a real structure in experiments. There may be also some other parameters such as the effects of boundary condition and the errors of experimental setup which cause discrepancy. However, the present method is found more reliable than the smearing method and CLT. There is just $5 \%$ of discrepancy comparing the present work with those of experiment, whereas the inconsistencies of $41 \%$ and $10 \%$ were presented by Crenwelge and Muster ${ }^{26}$ and

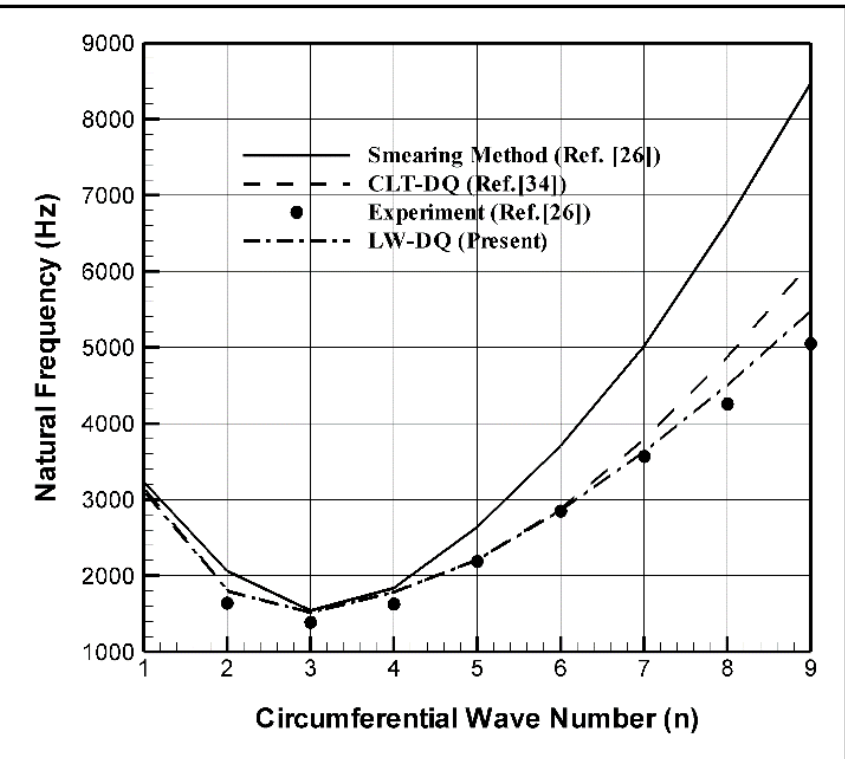

Figure 5. Variation of natural frequencies for the orthogonally stiffened isotropic conical shell with circumferential wave number in comparison between results of the present study and those reported in Crenwelge and Muster $^{26}$ and Daneshjou et al. ${ }^{34}\left(L / a=3.06, h / a=0.0292, \alpha=10^{\circ}\right.$, $m=1, N_{s}=6, N_{r}=3$ ).

Daneshjou et al., ${ }^{34}$ comparing the experimental results with those of smearing method and CLT.

\subsection{Parameter Studies}

The previous sections demonstrate the fast convergence behaviour and adaptability of the present method. Here the effects of number of stiffeners, axil load and external pressure on the natural frequency of the stiffened cylindrical shells are considered.

Figure 6 illustrates the effects of the number of rings on the frequencies of the stiffened rotating conical shell. In this case, the number of the stringers is 0 . It can be observed from this figure that at lower circumferential wave numbers, the number of rings demonstrates no significant effect. However, in high circumferential wave numbers, the frequency is raised by increasing the number of rings, whereas the increasing rate of gradient becomes small. However, the number of circumferential waves with occurrence of the fundamental frequency decreases when the number of rings is enhanced. For example, the fundamental frequency occurred at $n=8$ for $N_{r}=0$, and at $n=4$ for $N_{r}=10$. However, it is also seen from Fig. 6 that the frequencies of the shell show small change when rings number is increased from 8 .

Figure 7 depicts the effects from number of stringers on natural frequency of the non-rotating stringer-stiffened conical shell. In this case, the numbers of stringers are 0,10 and 20 , where no rings are applied. It can be observed that the effect of stringers is negligible at great numbers of circumferential wave. However, at lower circumferential wave numbers, particularly in frequencies smaller than the fundamental one, the frequency decreases slightly by increasing the number of stringers. This is because the radius of conical shell is increased along the axial axis and then the inertial forces of stringers are increased. Therefore, inertial terms of the stiffened shell are more considerable than those of the stiffness.

In Figs. 8-9, the effects of axial compressive load and external pressure on natural frequency of the stiffened conical shell 


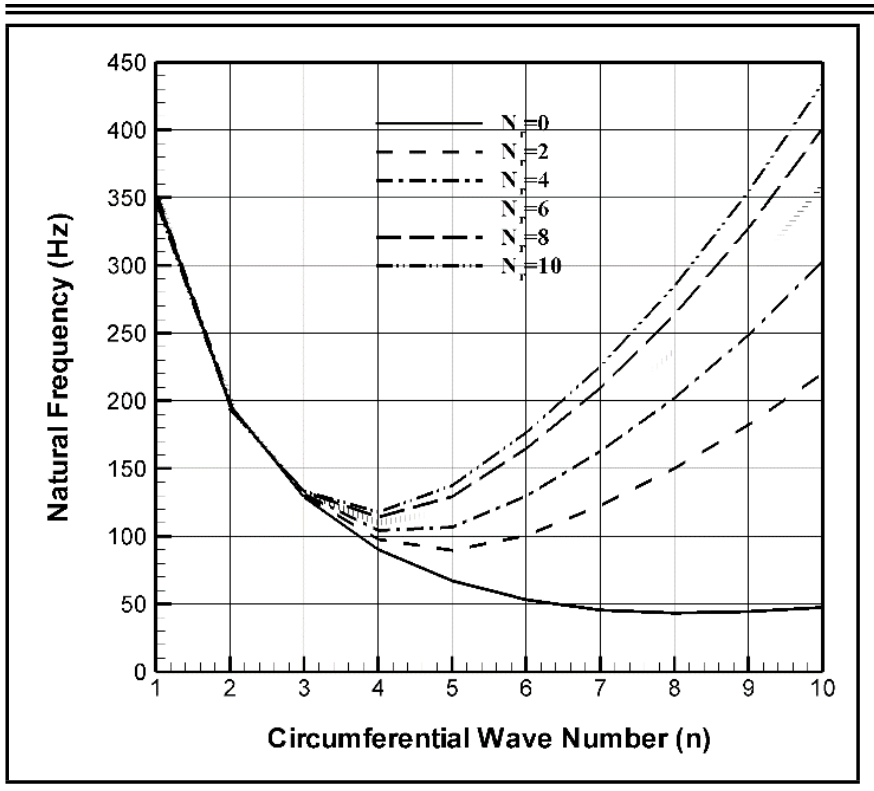

Figure 6. Variation of natural frequencies for the composite conical shell with circumferential wave number at various numbers of rings $(L=2 \mathrm{~m}, a=$ $\left.0.5 \mathrm{~m}, h=2 \mathrm{~mm}, \alpha=20^{\circ}, m=1,\left[0^{\circ} / 90^{\circ} / 0^{\circ}\right], \mathrm{Ss}-\mathrm{Sl}\right)$.

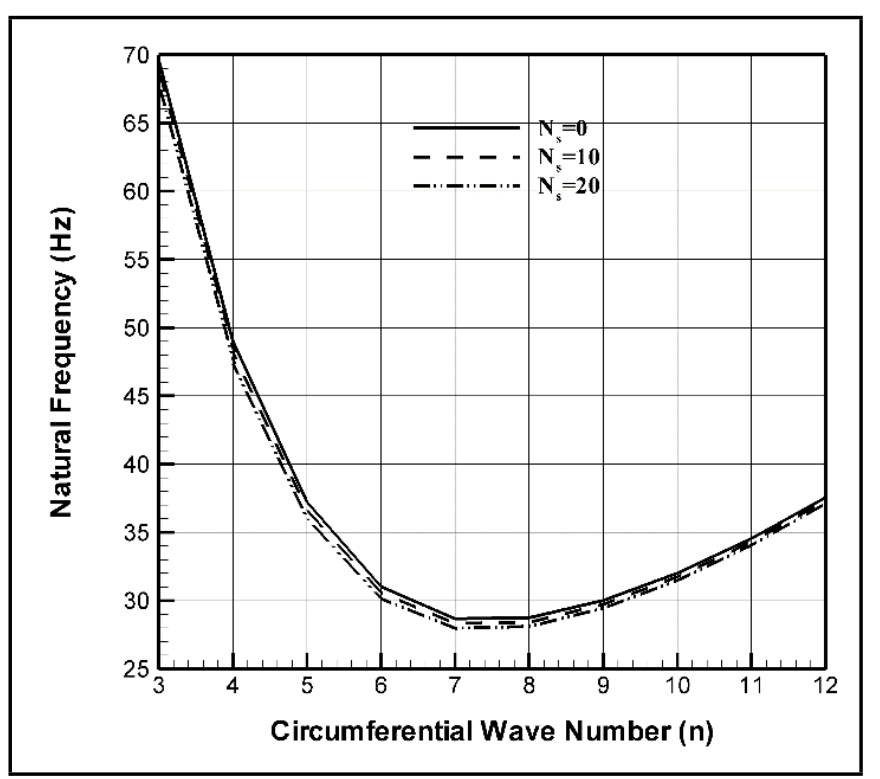

Figure 7. Variation of natural frequencies for the composite conical shell with circumferential wave number in various numbers of stringers $(L=4 \mathrm{~m}, a=$ $\left.0.5 \mathrm{~m}, h=2 \mathrm{~mm}, \alpha=20^{\circ}, m=1,\left[0^{\circ} / 90^{\circ} / 0^{\circ}\right], \mathrm{Ss}-\mathrm{Sl}\right)$.

are investigated, respectively. In this figures, $N_{c r}^{x}$ and $P_{c r}$ are used to address critical global buckling load and pressure of the conical shell, respectively, and it is important to note that the axial load and pressure must be a fraction of buckling load and pressure. The responses to axial compressive load and external pressure are having a down-shift. This is expected since compressive load and external pressure causes the shell to become flexible. Noteworthy is that the effect of these loading on fundamental frequency is more significant than other frequencies. In addition, it is noteworthy that, by raising the load, the level of sensitivity of frequency increases. Moreover, the frequency of the stiffened shell approaches to zero when the axial load or the external pressure tend to critical buckling or buckling pressure, respectively. This is another way to find the buckling load or pressure.

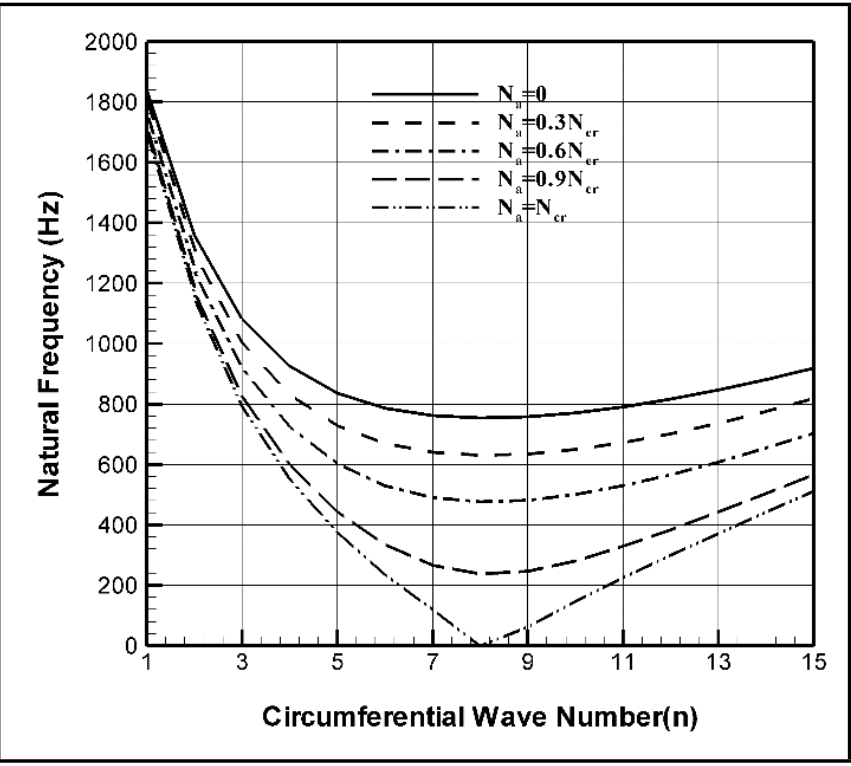

Figure 8. Sensitivity of natural frequencies of the stiffened composite conical shell to axial compressive load $(L=0.25 \mathrm{~m}, a=0.25 \mathrm{~m}, h=1 \mathrm{~mm}$, $\left.\alpha=30^{\circ}, m=1, N_{s}=5, N_{r}=0,\left[0^{\circ} / 90^{\circ} / 0^{\circ}\right], \mathrm{Ss}-\mathrm{Sl}\right)$.

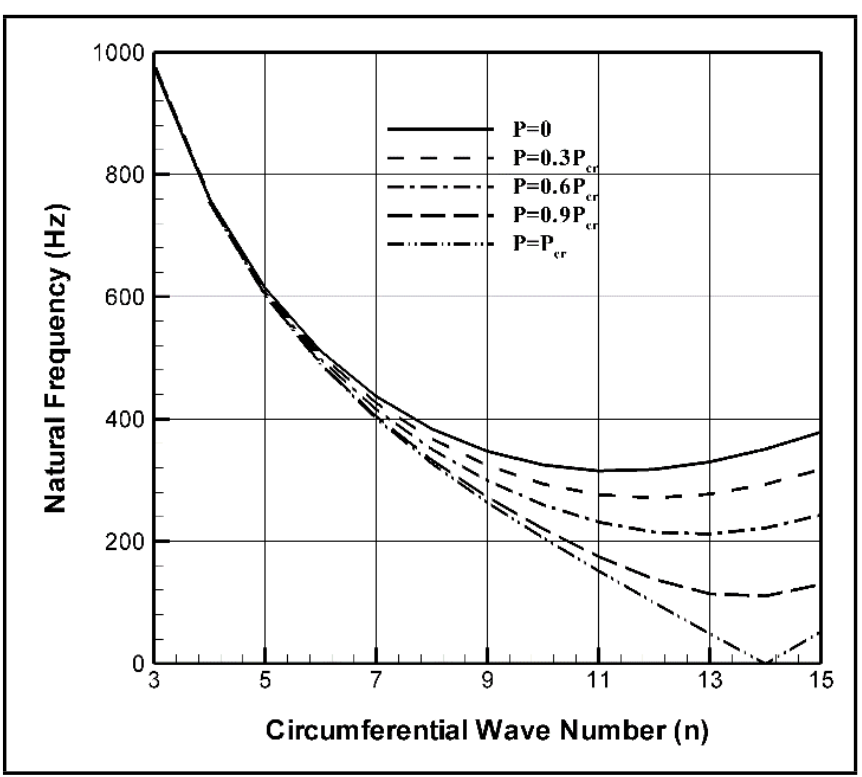

Figure 9. Sensitivity of natural frequencies of the stiffened composite conical shell to external pressure ( $L=1 \mathrm{~m}, a=0.25 \mathrm{~m}, h=1 \mathrm{~mm}, \alpha=30^{\circ}$, $\left.m=1, N_{s}=N_{r}=5,\left[0^{\circ} / 90^{\circ} / 0^{\circ}\right], \mathrm{Ss}-\mathrm{Sl}\right)$.

\section{CONCLUSIONS}

In this paper, the three-dimensional vibration analysis of stiffened, composite, conical shells under axial load and pressure is developed using a mixed layerwise-differential quadrature method. It is concluded that the mixed layerwisedifferential quadrature method can be used as a robust, effective, and accurate numerical method for vibration and buckling analysis of thick or thin stiffened conical shells. It is detected that the results are rapidly converged and the trend of convergence of the buckling load for conical shell with different cone angles behaves in the same way. In addition, using the rings in construction of conical shell leads to increase of natural frequency. However, the effect of stringers on natural frequency in first longitudinal mode is not sensible and it may be decreased. Therefore, application of stringer is not recommended unless the buckling phenomenon is significant. Moreover, the 
present method is in agreement with the experiments. There is only an average of $5 \%$ discrepancy between the present work and those of experimental results for a widely stiffened conical shell from $n=2$ to $n=9$. However, the inconsistency of $10 \%$ and $41 \%$ was reported by other researchers with the results of CLT and smearing method. Also, the effect of axial load and external pressure on fundamental frequency is more significant than other frequencies and by raising the load, the level of sensitivity of frequency increases.

\section{REFERENCES}

1 Baruch, M. and Sinner, J. Effect of eccentricity of stiffeners on the general stability of stiffened cylindrical shells under hydrostatic pressure, Journal of Mechanical Engineering Science, 5, 23-27, (1963). https://dx.doi.org/10.1243/JMES_JOUR_1963_005_005_02

2 Hedgepeth, J. M. and Hall, D. B. Stability of stiffened cylinders, AIAA Journal, 3, 2275-2286, (1965). https://dx.doi.org/10.2514/3.3357

3 Reddy, J. N. and Starnes, J. H. General buckling of stiffened circular cylindrical shells according to a layerwise theory, Computers \& Structures, 49 (4), 605-616, (1993). https://dx.doi.org/10.1016/0045-7949(93)90065-L

4 Patel, S. N., Datta, P. K., and Sheikh, A. H. Buckling and dynamic instability analysis of stiffened shell panels, Thin-Walled Structures, 44, 321-333, (2006). https://dx.doi.org/10.1016/j.tws.2006.03.004

5 Jiang, L., Wang, Y., and Wang, X. Buckling analysis of stiffened circular cylindrical panels using differential quadrature element method, Thin-Walled Structures, 46, 390-398, (2008). https://dx.doi.org/10.1016/j.tws.2007.09.004

6 Seide, P. Axisymmetrical buckling of circular cones under axial compression, Journal of Applied Mechanics, 23, 625628, (1956).

7 Arbocz, J. Buckling of conical shells under axial compression, Report for the NASA, Report no. CR-1162, (1968).

8 Tong, L., Tabarrok, B., and Wang, T. K. Simple solutions for buckling of orthotropic conical shells, International Journal of Solids and Structures, 29 (8), 933-946, (1992). https://dx.doi.org/10.1016/0020-7683(92)90067-4

9 Tong, L. and Wang, T. K. Buckling analysis of laminated composite conical shells, Composites Science and Technology, 47, 57-63, (1993). https://dx.doi.org/10.1016/02663538(93)90096-Y

$10 \mathrm{Wu}, \mathrm{C}$. P. and Chen, C. W. Elastic buckling of multilayered anisotropic conical shells, Journal of Aerospace Engineering , 14, 29-36, (1993). $\quad$ https://dx.doi.org/10.1061/(ASCE)08931321(2001)14:1(29)

11 Sofiyev, A. H. and Schnack, E. The buckling of cross-ply laminated non-homogeneous orthotropic composite conical thin shells under a dynamic external pressure, Acta Mechanica, 162, 29-40, (2003). https://dx.doi.org/10.1007/s00707-002-1001-2
12 Shadmehri, F., Hoa, S. V., and Hojjati, M. Buckling of conical composite shells, Composite Structures, 94, 787-792, (2012). https://dx.doi.org/10.1016/j.compstruct.2011.09.016

13 Nedelcu, M. GBT formulation to analyse the buckling behaviour of isotropic conical shells, Thin-Walled Structures, 49, 812-818, (2011). https://dx.doi.org/10.1016/j.tws.2011.02.006

14 Sofiyev, A. H. and Kuruoglu, N. Buckling of nonhomogeneous orthotropic conical shells subjected to combined load, Steel and Composite Structures, 19, 1-19, (2015). https://dx.doi.org/10.12989/scs.2015.19.1.001

15 Sofiyev, A. H. Buckling of heterogeneous orthotropic composite conical shells under external pressures within the shear deformation theory, Composites Part B: Engineering, 84, 175-187, (2016). https://dx.doi.org/10.1016/j.compositesb.2015.08.058

16 Spagnoli, A. and Chryssanthopoulos, M. K. Elastic buckling and postbuckling behaviour of widely-stiffened conical shells under axial compression, Engineering Structures, 21, 845-855, (1999). https://dx.doi.org/10.1016/S01410296(98)00036-4

17 Spagnoli, A. and Chryssanthopoulos, M. K. Buckling design of stringer-stiffened conical shells in compression, Journal of Structural Engineering, 125 (1), 40-48, (1999). https://dx.doi.org/10.1061/(ASCE)07339445(1999)125:1(40)

18 Spagnoli, A. Different buckling modes in axially stiffened conical shells, Engineering Structures, 23, 957-965, (2001). https://dx.doi.org/10.1016/S0141-0296(00)001127

19 Sivadas, K. R. and Ganesan, N. Vibration analysis of laminated conical shells with variable thickness, Journal of Sound and Vibration, 148, 477-491, (1991). https://dx.doi.org/10.1016/0022-460X(91)90479-4

20 Thambiratnam, D. P. and Zhuge, Y. Axisymmetric free vibration analysis of conical shells, Engineering Structures, 15, 83-89, (1993). https://dx.doi.org/10.1016/01410296(93)90002-L

21 Tong, L. Y. Free vibration of orthotropic conical shells, International Journal of Engineering Science, 31, 719-733, (1993). https://dx.doi.org/10.1016/0020-7225(93)90120-J

22 Tong, L. Y. Free vibration of composite laminated conical shells, International Journal of Mechanical Sciences, 35, 47-61, (1993). https://dx.doi.org/10.1016/00207403(93)90064-2

23 Sofiyev, A. H., Korkmaz, K. A., Mammadov, Z., and Kamanli, M. The vibration and buckling of freely supported non-homogeneous orthotropic conical shells subjected to different uniform pressures, International Journal of Pressure Vessels and Piping, 86, 661-668, (2009). https://dx.doi.org/10.1016/j.ijpvp.2009.03.012

24 Sofiyev, A. H., Kuruoglu, N., and Halilov, H. M. The vibration and stability of non-homogeneous orthotropic conical shells with clamped edges 
subjected to uniform external pressures, Applied Mathematical Modelling, 34, 1807-1822, (2010). https://dx.doi.org/10.1016/j.apm.2009.09.025

25 Najafov, A. M., Sofiyev, A. H., Hui, D., Kadioglu, F., Dorofeyskaya, N. V., and Huang, H. Non-linear dynamic analysis of symmetric and antisymmetric cross-ply laminated orthotropic thin shells, Meccanica, 49 (2), 413-427, (2014). https://dx.doi.org/10.1007/s11012-013-9802-z

26 Crenwelge, O. E. and Muster, D. Free vibration of ring and stringer stiffened conical shells, The Journal of the Acoustical Society of America, 46, 176-185, (1969). https://dx.doi.org/10.1121/1.1911667

27 Rao, S. S. and Reddy, E. S. Optimum design of stiffened conical shells with natural frequency constraints, Computers \& Structures, 14, 103-110, (1981). https://dx.doi.org/10.1016/0045-7949(81)90089-4

28 Langley, R. S. A dynamic stiffness technique for the vibration analysis of stiffened shell structures, Journal of Sound and Vibration, 156, 521-540, (1992). https://dx.doi.org/10.1016/0022-460X(92)90742-G

29 Raj, D. M., Narayanan, R., Khadakkar, A. G., and Paramasivam, V. Effect of ring stiffeners on vibration of cylindrical and conical shell models, Journal of Sound and Vibration, 179, 413-426, (1995). https://dx.doi.org/10.1006/jsvi.1995.0027

30 Mecitoğlu, Z. Vibration characteristics of a stiffened conical shell, Journal of Sound and Vibration, 197 (2), 191-206, (1996). https://dx.doi.org/10.1006/jsvi.1996.0525

31 Goldfeld, Y. Elastic buckling and imperfection sensitivity of generally stiffened conical shells, AIAA Journal, 45 (3), 721-729, (2007). https://dx.doi.org/10.2514/1.25830

32 Jabareen, M. and Sheinman, I. Stability of imperfect stiffened conical shells, International Journal of Solids and Structures, 46 (10), 2111-2125, (2009). https://dx.doi.org/10.1016/j.ijsolstr.2008.07.029

33 Farkas, J., Jármai, K., and Orbán, F. Cost minimization of a ring-stiffened conical shell loaded by external pressure, Welding in the World, 52 (5-6), 110-115, (2008). https://dx.doi.org/10.1007/BF03266645

34 Daneshjou, K., Talebitooti, M., Talebitooti, R., and Googarchin, H. S. Dynamic analysis and critical speed of rotating laminated conical shells with orthogonal stiffeners using generalized differential quadrature method, Latin American Journal of Solids and Structures, 10, 349-190, (2013). https://dx.doi.org/10.1590/S1679-78252013000200007

35 Khdeir, A. A., Reddy, J. N., and Frederick, D. A study of bending, vibration and buckling of cross-ply circular cylindrical shells, International Journal of Engineering Science, 27, 1337-1351, (1989). https://dx.doi.org/10.1016/00207225(89)90058-X

36 Lam, K. Y. and Wu, Q. Vibrations of thick rotating laminated composite cylindrical shells, Journal of Sound and Vibration, 225, 483-501, (1999). https://dx.doi.org/10.1006/jsvi.1999.2205
37 Toorani, M. H. and Lakis, A. A. General equations of anisotropic plates and shells including transverse shear deformations, rotary inertia and initial curvature effects, Journal of Sound and Vibration, 237, 561-615, (2000). https://dx.doi.org/10.1006/jsvi.2000.3073

38 Auricchio, F. and Sacco, E. Refined first-order shear deformation theory models for composite laminates, Journal of Applied Mechanics, 70, 381-390, (2003). https://dx.doi.org/10.1115/1.1572901

39 Reddy, J. N. Mechanics of Laminated Composite Plates and Shells: Theory and Analysis, 2nd ed., CRC press, New York, (2004).

40 Qatu, M. S. Vibration of Laminated Shells and Plates, 1st ed., Elsevier Ltd, Amsterdam, (2004).

41 Tornabene, F. Free vibration analysis of functionally graded conical, cylindrical shell and annular plate structures with a four-parameter power-law distribution, Computer Methods in Applied Mechanics and Engineering, 198, 2911-2935, (2009). https://dx.doi.org/10.1016/j.cma.2009.04.011

42 Oktem, A. S. and Soares, C. G. Analysis of the static response of cross-ply simply supported plates and shells based on a higher order theory, Mechanics of Composite Materials, 48 (1), 65-76, (2012). https://dx.doi.org/10.1007/s11029-012-9252-z

43 Liew, K. M., Ng, T. Y., and Zhang, J. Z. Differential quadrature-layerwise modeling technique for three dimensional analysis of cross-ply laminated plates of various edge supports, Computer Methods in Applied Mechanics and Engineering, 191, 3811-3832, (2002). https://dx.doi.org/10.1016/S0045-7825(02)00309-2

44 Malekzadeh, P., Setoodeh, A. R., and Barmshouri, E. A hybrid layerwise and differential quadrature method for in-plane free vibration of laminated thick circular arches, Journal of Sound and Vibration, 315, 212-225, (2008). https://dx.doi.org/10.1016/j.jsv.2008.02.005

45 Heydarpour, Y., Malekzadeh, P., Golbahar Haghighi, M. R., and Vaghefi, M. Thermoelastic analysis of rotating laminated functionally graded cylindrical shells using layerwise differential quadrature method, Acta Mechanica, 223 (1), 81-93, (2012). https://dx.doi.org/10.1007/s00707011-0551-6

46 Setoodeh, A. R., Tahani, M., and Selahi, E. Hybrid layerwise-differential quadrature transient dynamic analysis of functionally graded axisymmetric cylindrical shells subjected to dynamic pressure, Composite Structures, 93, 2663-2670, (2011). https://dx.doi.org/10.1016/j.compstruct.2011.06.011

47 Reddy, J. N. A generalization of two-dimensional theories of laminated composite plates, Communications in Applied Numerical Methods, 3, 173-180, (1987). https://dx.doi.org/10.1002/cnm.1630030303

48 Bellman, R. E. Methods of Nonlinear Analysis, Academic Press, New York, (1973).

49 Shu, C. Differential Quadrature and Its Application in Engineering, Springer, Berlin, (2000). 